\title{
ESPLENECTOMIA LAPAROSCÓPICA NAS DOENÇAS HEMATOLÓGICAS
}

\section{LAPAROSCOPIC SPLENECTOMYIN HEMATOLOGICAL DISORDERS}

\author{
Antônio Aldo Melo-Filho, ACBC-CE ${ }^{1}$ \\ Márcio Lopes Miranda, TCBC-SP ${ }^{2}$ \\ Antônio Gonçalves de Oliveira-Filho, TCBC-SP2 \\ Vitória Régia Pinheiro ${ }^{3}$ \\ Nelson Ari Brandalise, TCBC-SP \\ Joaquim Murray Bustorff-Silva ${ }^{5}$
}

\begin{abstract}
RESUMO: Objetivo: Relatar a experiência inicial do Centro Infantil Boldrini com a esplenectomia laparoscópica (EL) em crianças e adultos jovens. Método: Foram revisados os prontuários de 40 pacientes (mediana da idade de 6,6 anos; 1 a 22,8) submetidos à EL entre Julho de 2000 e Maio de 2002. As principais indicações de acordo com a doença de base foram: doença falciforme (DF) em 20 pacientes (50\%), esferocitose hereditária em 10 ( $25 \%$ ), púrpura trombocitopência idiopática em oito (20\%), doença de Hodgkin em um e anemia hemolítica a esclarecer em um. Resultados: Trinta e oito esplenectomias foram completadas por via laparoscópica (duas conversões) e em doze foi realizada adicionalmente a colecistectomia. A mediana do tempo operatório foi de 127,5 minutos (90 - 240 min) e sete (17,5\%) baços acessórios foram encontrados. Sangramento intra-operatório foi significativo apenas nas duas conversões, mas não houve necessidade de transfusões. A mediana do peso dos baços foi de $250 \mathrm{~g}(106-1000 ; \mathrm{n}=36)$. Complicações pós-operatórias ocorreram em sete $(17,5 \%)$ pacientes e, nos portadores de DF, $35 \%$ desenvolveram síndrome torácica aguda. A mediana da permanência hospitalar pós-operatória foi de dois dias (2 - 14). O seguimento variou de 23 dias a dois anos (mediana de 11 meses). Conclusões: A EL pode ser realizada de modo seguro mesmo em baços de grande tamanho e é opção atrativa que pode substituir o procedimento aberto. Em pacientes com DF, a taxa de complicações permanece alta, sugerindo mecanismos outros que vão além da escolha da via de acesso cirúrgica.
\end{abstract}

Descritores : Laparoscopia; Esplenectomia; Doença falciforme

\section{INTRODUÇÃO}

O tratamento de algumas doenças hematológicas é baseado na esplenectomia. No sentido de minimizar os riscos e aumentar os benefícios deste procedimento, a cirurgia minimamente invasiva foi introduzida. Atualmente, muitos centros têm adotado a esplenectomia laparoscópica (EL) como opção viável, mas preocupações permanecem acerca do manejo da esplenomegalia e de baços acessórios ${ }^{1,2}$. Ademais, embora os custos e o tempo operatório do procedimento tenham sido reduzidos, eles ainda são maiores que aqueles da esplenectomia aberta (EA) ${ }^{3,4}$.

O objetivo deste estudo foi relatar a experiência inicial do Centro Infantil Boldrini com EL em crianças e adultos jovens.

1. Pós-graduando - Disciplina de Cirurgia Pediátrica - UNICAMP

2. Médico Assistente - Disciplina de Cirurgia Pediátrica - UNICAMP e Centro Infantil Boldrini

3. Coordenadora do Departamento de Hematologia - Centro Infantil Boldrini

4. Professor Adjunto - Disciplina de Gastrocirurgia - UNICAMP

5.Professor Assistente Doutor e Coordenador da Disciplina de Cirurgia Pediátrica - UNICAMP

Recebido em 04/02/2003

Aceito para publicação em 12/08/2003

Trabalho realizado no Centro Infantil Boldrini - Campinas-SP 


\section{MÉTODO}

Foram revisados os prontuários de 40 pacientes que foram submetidos à EL, entre Julho/ $2000 \mathrm{e}$ Maio/ 2002. A casuística é composta de 18 (45\%) pacientes do sexo masculino e 22 (55\%) do sexo feminino (Tabela 1). A mediana da idade foi de 6,6 anos (1 a 22,8$)$, e $33(82,5 \%)$ pacientes tinham menos de 12 anos de idade.

As indicações para EL foram: crises de seqüestro esplênico major na anemia falciforme (SS) (10 casos - $25 \%)$, S $\beta$ talassemia (5 casos - 12,5\%) e hemoglobinopatia SC (SC) (5 casos - 12,5\%), hiperesplenismo na esferocitose hereditária (10 casos - $25 \%$ ), púrpura trombocitopênica idiopática $(8$ casos - $20 \%$ ) e anemia hemolítica a/e (1 caso - 2,5\%) e diagnóstica na doença de Hodgkin (1 caso - 2,5\%). A ultrassonografia pré-operatória foi realizada para avaliar o tamanho do baço, procurar baços acessórios e, em caso de doença hemolítica, detectar colelitíase e avaliar a árvore biliar. Todos os pacientes foram imunizados com vacinas anti-pneumocóccica e antihaemophilus pelo menos três semanas antes da EL e receberam profilaxia com penicilina. Para pacientes com doença falciforme, o regime conservador de transfusão pré-operatória recomendado por Vichinsky et $a l^{5}$ foi seguido, e os pacientes transfundidos até alcançar o nível de $10 \mathrm{~g} / \mathrm{dL}$ de hemoglobina.

Técnica operatória: sob anestesia geral e após passagem de sonda nasogástrica, o paciente é posicionado em decúbito lateral direito a $60^{\circ} \mathrm{e} \mathrm{em}$ posição de proclive a $15^{\circ}$ para melhorar a visualização do campo operatório. $\mathrm{O}$ pneumoperitônio é realizado pela insuflação de $\mathrm{CO}_{2}$ através de agulha de Verres até alcançar pressão de $10-15 \mathrm{mmHg}$. Após isto, quatro trocartes são inseridos. Dois trocartes de 10 mm são posicionados: um na região periumbilical (para uma ótica de $30^{\circ}$ ) e outro no quadrante inferior esquerdo. Dois trocartes adicionais de $5 \mathrm{~mm}$ são inseridos: um próximo ao xifóide e outro no quadrante superior direito próximo à linha média (para ajudar na báscula do baço). Quando necessário, um quinto trocarte é introduzido no quadrante inferior direito para auxílio na colecistectomia. A dissecação inicia-se com a mobilização do pólo inferior do baço, seguido da divisão dos vasos gástricos curtos, utilizando um gancho, pinça bipolar ou bisturi harmônico. O próximo passo é o controle do hilo esplênico pela oclusão separada, em progressão cefálica, de artérias e veias por clip metálico, ligadura com fio ou grampeador vascular laparoscópico. Ao final, os ligamentos laterais são liberados e procede-se à busca de possíveis baços acessórios. A colecistectomia quando indicada, é realizada após reposicionamento do paciente em decúbito dorsal horizontal. $\mathrm{O}$ baço é então colocado em uma bolsa plástica resistente introduzida via trocarte esquerdo de $10 \mathrm{~mm}$. A abertura desta bolsa é retirada através do trocarte umbilical e tal incisão é ampliada em 2-4 cm para evitar sua ruptura. $\mathrm{O}$ baço é seccionado digitalmente e removido com auxílio de pinças e aspirador. Por fim, o campo operatório é inspecionado e realiza-se a síntese da parede abdominal com suturas absorvíveis e a sonda nasogástrica é removida.

\section{RESULTADOS}

Todos os casos, exceto dois, foram resolvidos por via laparoscópica e, em 12 pacientes (30\%), foi realizada adicionalmente a colecistectomia (Tabela 1). Analisando os 38 pacientes em que a EL foi realizada, observa-se que a mediana do tempo operatório foi de 117,5 minutos ( 80 - $260 \mathrm{~min})$ e 182,5 minutos $(120$ - 240) para o grupo submetido à EL exclusiva e EL com colecistectomia, respectivamente.

Sete $(17,5 \%)$ baços acessórios foram encontrados em quatro pacientes com doença falciforme (DF), dois com esferocitose e em um com doença de Hodgkin.

Houve sangramento intra-operatório significativo em dois pacientes com púrpura e sangramento no sistema nervoso central devido a plaquetopenia severa, que necessitaram conversão por instabilidade clínica, mas sem necessidade de transfusões. A mediana do peso do baço foi de $250 \mathrm{~g}$ (106 - 1000; $\mathrm{n}=36$ ). Em dois casos, os dados a respeito do peso do baço não foram encontrados nos prontuários.

Ocorreram complicações pós-operatórias em sete $(17,5 \%)$ pacientes que evoluíram com síndrome torácica aguda (STA) (5 SS e 2 SC).

A mediana da permanência hospitalar pósoperatória foi de dois dias (2 - 24). A maioria dos pacientes $(55 \%)$ recebeu dieta por via oral após 24 horas da operação e alta hospitalar no segundo dia pós-operatório. O seguimento dos pacientes variou de 23 dias a dois anos (mediana de 11 meses). A doença sobrejacente permaneceu sob controle em todos os pacientes, exceto em três. Dois pacientes com PTI apresentaram resposta transitória pós-operatória, mas a cintilografia realizada após a recidiva não eviden- 
Tabela 1 - Aspectos demográficos e resultados perioperatórios.

\begin{tabular}{|c|c|}
\hline & $\begin{array}{c}\text { Esplenectomia } \\
(n=40)\end{array}$ \\
\hline Idade (anos) mediana (variação) & $6,6 \quad(1-22,8)$ \\
\hline \multicolumn{2}{|l|}{ Sexo } \\
\hline Masculino & $18 \quad(45 \%)$ \\
\hline Feminino & $22 \quad(55 \%)$ \\
\hline \multicolumn{2}{|l|}{ Diagnóstico hematológico } \\
\hline Doença falciforme & $20 \quad(50 \%)$ \\
\hline Esferocitose hereditária & $10 \quad(25 \%)$ \\
\hline Púrpura trombocitopência idiopática & $8 \quad(20 \%)$ \\
\hline Outros & $2(5 \%)$ \\
\hline Colecistectomia adicional & $(30 \%)$ \\
\hline Baço acessório & $(17,5 \%)$ \\
\hline Transfusão intra-operatória & 0 \\
\hline Conversão para procedimento aberto & $2 \quad(5 \%)$ \\
\hline Tempo operatório (min) mediana (variação) & $127,5(90-240)$ \\
\hline Peso do baço (g) mediana (variação) & $250(106-1000)^{*}$ \\
\hline Permanência hospitalar pós-op (dias) mediana (variação) & $2 \quad(2-24)$ \\
\hline
\end{tabular}

* Peso do baço de 36 pacientes.

ciou baço acessório. O terceiro paciente (anemia hemolítica) evoluiu com persistência da pancitopenia e, após três meses, apresentou sangramento de SNC e faleceu.

\section{DISCUSSÃO}

Após a primeira descrição de EL em 1991, consecutivos relatos em crianças foram publicados por Tulman et $a l^{6}$ e Lobe et $a l^{7}$. Assim como a maioria dos procedimentos laparoscópicos, a EL foi ganhando aceitação entre os cirurgiões e passou a ser adotada como método de escolha para esplenectomia eletiva ${ }^{2}$.

A EL pode ser realizada em decúbito dorsal horizontal, mas trabalhos recentes têm relatado melhores resultados com a abordagem em decúbito late$\mathrm{ral}^{2,8,9}$. Tem sido nossa prática realizar a EL em decúbito lateral parcial, porque ela permite uma boa visualização do hilo esplênico. Ademais, quando necessário, torna-se mais fácil a realização de uma colecistectomia adicional, pois a mudança no decúbito é realizada somente com o auxílio da mesa cirúrgica, sem a necessidade de mobilização do paciente.

Uma das controvérsias a respeito da cirurgia laparoscópica é se ela oferece os mesmos benefícios que a cirurgia aberta, sem maior taxa de complica- ção. Neste sentido, a identificação e remoção de baços acessórios bem como uma cuidadosa manipulação e remoção do baço são aspectos importantes. A recorrência pós-esplenectomia na PTI pode ocorrer por função esplênica residual ${ }^{10,11}$. Em estudo de 60 pacientes com PTI que foram submetidos à EL, Szold et al ${ }^{11}$. encontraram sete pacientes com trombocitopenia recorrente, ocasionada pela persistência de baços acessórios em dois deles . No intuito de evitar tal situação, rotineiramente realizamos avaliação ultra-sonográfica pré-operatória e reservamos a cintilografia somente para os casos de persistência de plaquetopenia pós esplenectomia. Contudo, sabese que mesmo com a tomografia computadorizada ou a cintilografia com hemácias marcadas com tecnécio 99m, um grande número de baços acessórios pode não ser identificado no pré-operatório ${ }^{12}$. Isto reforça o papel do cuidadoso exame dos ligamentos esplenocólico e gastrocólico, hilo esplênico, cauda do pâncreas e grande omento no intra-operatório. Adicionalmente, todos os esforços devem ser feitos para evitar lesões de parênquima ou derramamento durante a remoção do baço. Trabalhos recentes relatam taxas similares de identificação de baço acessório durante EL ou esplenectomia aberta (EA), variando de $10 \%$ a $30 \%{ }^{13,14}$. Na presente série, $17,5 \%$ dos pacientes tinham baços acessórios que foram remo- 
vidos apropriadamente e não houve ruptura da bolsa utilizada para remoção do baço. Não foi encontrado baço acessório entre os oito pacientes com PTI. Dois destes, contudo, persistiram com plaquetopenia e a investigação subseqüente com cintilografia também não revelou baço acessório. Szold et al relataram uma resposta total na PTI de $88 \%$ e a cintilografia (considerado o método mais sensível para esta finalidade) não demonstrou baço acessório em cinco de sete pacientes com PTI recidivada ${ }^{11}$.

Os resultados deste estudo corroboram que a EL é uma opção segura. A despeito de duas conversões secundárias a sangramento intra-operatório, nenhuma transfusão intra ou pós-operatória imediata foi requerida. Nos casos iniciais, foi realizada rotineiramente a ligadura separada de artérias e veias com clips para o controle do hilo. Em três pacientes, incluindo aqueles com baços pesando $980 \mathrm{~g}$ e $560 \mathrm{~g}$, uma ligadura com fio foi utilizada, e em quatro pacientes foi empregado o grampeador vascular.

Atualmente vários autores realizam a secção de vasos do hilo em conjunto com um grampeador vascular ao invés da ligadura individual, reduzindo assim a hemorragia intra-operatória ${ }^{8,15}$. Isto é particularmente útil quando o padrão vascular do hilo esplênico é do tipo marginal ${ }^{2}$. Outra melhoria técnica é a utilização do bisturi harmônico que simplifica a divisão de vasos de pequeno e médio calibre, reduz o tempo operatório, diminui a incidência de sangramento significativo e, devido ao preciso ponto de impacto, promove mínima lesão térmica tecidual adjacente.

A esplenomegalia é a principal dificuldade técnica em EL. Inicialmente ela era considerada uma contra-indicação, mas a curva de aprendizado e a melhoria técnica alteraram esta situação ${ }^{8,15}$. Walsh et $a{ }^{16}$. descreveram que a EL é factível e segura mesmo na esplenomegalia associada a linfomas . Parece que o principal problema não é o tamanho do baço per se, mas a razão entre o tamanho do baço e o campo operatório ${ }^{8}$. Indubitavelmente é mais difícil realizar uma EL quando o pneumoperitônio não oferece um bom espaço para trabalhar. O presente estudo também mostra que a EL pode ser realizada em baços tão grandes quanto $1 \mathrm{Kg}$. Alguns autores têm aconselhado o uso da embolização da artéria esplênica pre-operatória para reduzir o tamanho do baço ${ }^{17}$. Contudo, sua utilidade tem sido contestada por muitos uma vez que costuma estar associada a complicações como dor e abscesso, sem redução significativa das necessidades de transfusão ${ }^{8,15,18}$. Recentemen- te, em adultos, a cirurgia laparoscópica com assistência da mão (hand port surgery) também tem sido recomendada. Em um estudo internacional, Litwin et al ${ }^{19}$. defenderam que tal técnica permite melhor manipulação do baço e mais fácil ensacamento do mesmo para remoção, além de possibilitar imediata hemostasia . Contudo, em crianças, é duvidoso se esta abordagem representaria uma vantagem sobre a cirurgia aberta. No presente trabalho, um paciente de 11 anos de idade com um baço de $980 \mathrm{~g}$ foi submetido à EL e colecistectomia, a operação durou 220 minutos e foi completada com sucesso.

A morbidade neste estudo deve ser analisada no contexto da doença subjacente, desde que a DF foi o principal diagnóstico em $55 \%$ (20) dos pacientes. Esta série difere da maioria de outros relatos, nos quais a esferocitose ou a PTI foram as indicações mais comuns para EL 1, 4, 13, 14, 20 . Complicações potencialmente fatais relacionadas à DF tais como crises de sequestro esplênico são bem conhecidas pelos cirurgiões ${ }^{21}$. Nestes pacientes, a esplenectomia tem sido defendida como uma alternativa a programas de transfusão crônica. A remoção do baço pode prevenir óbitos sem aumentar o risco de episódios de bacteremia ${ }^{21-23}$. Por outro lado, pacientes esplenectomizados permanecem em risco para complicações como crise de dor e STA, justificando as preocupações acerca de hidratação e oxigenação. Recentemente, Wright et al ${ }^{22}$. descreveram que a STA foi mais comum entre pacientes esplenectomizados . Após a introdução da laparoscopia, a taxa de STA pós-operatória permaneceu inalterada ${ }^{24,25}$. Em crianças, Delatte et $a l^{24}$. verificaram que a incidência de STA pós-operatória foi de $10,2 \%$ (seis casos) e que a maioria (cinco de seis casos) ocorreram após procedimento laparoscópico. Outro estudo relatou STA em duas de sete crianças com DF após EL e foi associada com permanência hospitalar prolongada (9 \pm 2 vs $3 \pm 2$ dias; $p<0,05)^{25}$. Parece que a transfusão pré-operatória no intuito de obter um nível de hemoglobina de $10 \mathrm{~g} / \mathrm{dL}$ reduz a morbidade, mas isto ainda é objeto de controvérsia ${ }^{5}$. No presente estudo, a incidência de STA pós-operatória em crianças com DF foi de $35 \%$ (sete de 20 casos), todos com nível de hemoglobina ao redor de $10 \mathrm{~g} / \mathrm{dL}$.

Outros fatores responsáveis pelo aparecimento da STA são a deficiência de imunidade celular e humoral ${ }^{26}$ e o polimorfismo de DNA ${ }^{27}$. Observa-se, por exemplo, uma alta incidência de STA nas crianças entre dois e quatro anos de idade, devido ao não 
desenvolvimento de anticorpos para uma variedade de microorganismos virais e bacterianos ${ }^{26}$. Por sua vez, as manifestações clínicas nos três maiores haplótipos africanos (Benin, Bantu e Senegal) diferem quanto à gravidade devido à diferença entre níveis de hemoglobina total e fetal, sendo o haplótipo de Bantu, relacionado a maior gravidade devido aos baixos níveis de hemoglobina fetal, a qual exerce um papel protetor ${ }^{27}$.

A mediana dos pacientes com doença falciforme foi de 4,1 anos (14 a 139 meses), o que condiz com a faixa etária de maior risco para STA. Outra provável justificativa para a alta incidência de STA nesta casuística se deve ao fato de que a maioria da população com DF do Estado de São Paulo Brasil é portadora do haplótipo de Bantu ${ }^{28}$.

Estudos retrospectivos realizados em crianças demonstraram que, embora a EL requeira um tempo operatório mais prolongado que a EA, aquela é associada com dor pós-operatória e permanência hospitalar reduzidas e um custo hospitalar total comparável $^{3,4,13,14}$. Recentemente, Rescorla et al ${ }^{13}$. descre- veram que a EL resultou em menor custo hospitalar total que a EA . A EL requer um maior investimento em equipamentos, mas, considerando que a maioria dos instrumentos é reutilizável, tais custos podem ser reduzidos. Além disso, a partir do aprimoramento das habilidades da equipe cirúrgica (curva de aprendizado), o tempo operatório e a permanência hospitalar são minimizados, compensando o gasto inicial.

O conhecimento de que a EL pode ser realizada de modo seguro, mesmo para remover baços de grande tamanho, e considerando suas vantagens como menor intensidade de dor, retorno mais precoce às atividades usuais, melhor resultado estético e baixa morbidade, torna a via laparoscópica uma opção atrativa à EA no tratamento de diferentes desordens hematológicas. Em contrapartida, em pacientes com DF, a taxa de complicações pós-operatórias permanece alta, e sugere que outros mecanismos não relacionados ao tipo de acesso cirúrgico possam estar envolvidos e merecem investigação adicional.

\begin{abstract}
Background: Laparoscopic splenectomy $(L S)$ is becoming the procedure of choice in the treatment of children with hematological disorders. However, concerns remains regarding conversion rates, dissection and extraction of the spleen. The authors analyze their early experience at Boldrini's Children Cancer Center-Brazil in 40 LS performed in children and young adults. Methods: Retrospective review of the charts of 40 patients (median age of 6.6 years; range 1 to 22.8) who underwent LS, between July/2000 and May/2002. The main indications were sickle cell disease (SCD) (20 - 50\%), hereditary spherocytosis (10 - $25 \%$ ) and idiopathic thrombocytopenic purpura (8-20\%). Results: All but two splenectomies were performed exclusively by laparoscopy, and 12 patients also underwent a concomitant cholecystectomy. The mean operating time was 127.5 minutes $(90-240 \mathrm{~m})$. In seven patients $(17.5 \%)$ accessory spleens were found and removed. Intraoperative bleeding was significant only in the two cases that required conversion to an open procedure, although no transfusion was needed. The median weight of the spleen was $250 \mathrm{~g}$ (range $106 \mathrm{~g}-1000 \mathrm{~g} ; \mathrm{n}=36$ ). Complications were observed in seven patients $(17.5 \%$ ) with SCD that developed acute chest syndrome. There were no deaths in this series and the median postoperative stay at the hospital was two days (2 - 14). Follow-up ranged from 23 days to two years. Conclusions: On the basis of our experience, LS is a safe procedure, even to treat large spleens and became an attractive option that might replace the open procedure. In SCD patients, the rate of complications remains high, suggesting mechanisms other than the scope of the choice of surgical approach.
\end{abstract}

Key words: Laparoscopy; Splenectomy; Sickle cell disease.

\section{REFERÊNCIAS}

1. Esposito C, Schaarschmidt K, Settimi A, et al Experience with laparoscopic splenectomy. J Pediatr Surg, 2000, 36: 309-311.
2. Katkhouda N, Mavor E - Laparoscopic splenectomy. Surg Clin North Am, 2000, 80: 1285-1297.

3. Farah RA, Rogers ZR, Thompson WR, et al-Comparison of laparoscopic and open splenectomy in children with hematologic disorders. JPediatr, 1997, 131:41-46. 
4. Janu PG, Rogers DA, Lobe TE - A comparison of laparoscopic and traditional open splenectomy in childhood. J Pediatr Surg, 1996, 31: 109-114.

5. Vichinsky EP, Haberkern CM, Neumayr L, et al - A comparison of conservative and aggressive transfusion regimens in the perioperative management of sickle cell disease. The Preoperative Transfusion in Sickle Cell Disease Study Group. N Engl J Méd, 1995, 333: 206-213.

6. Tulman S, Holcomb GW 3rd, Karamanoukian HL, et al - Pediatric laparoscopic splenectomy. J Pediatr Surg, 1993, 28: 689-692.

7. Lobe TE, Presbury GJ, Smith BM, et al - Laparoscopic splenectomy. Pediatr Ann, 1993, 22: 671-674.

8. Park AE, Birgisson G, Mastrangelo MJ, et al Laparoscopic splenectomy: outcomes and lessons learned from over 200 cases. Surgery, 2000, 128: 660667.

9. Ng WT, Lee KW - Control of hemorrhage during laparoscopic splenectomy. Surgery, 2001, 129: 652.

10. Targarona EM, Espert JJ, Balague C, et al - Residual splenic function after laparoscopic splenectomy: a clinical concern. Arch Surg, 1998, 133: 56-60.

11. Szold A, Schwartz J, Abu-Abeid S, et al - Laparoscopic splenectomies for idiopathic thrombocytopenic purpura: experience of sixty cases. Am J Hematol, 2000, 63:7-10.

12. Gigot JF, de Ville de Goyet J, Van Beers BE, et al Laparoscopic splenectomy in adults and children: experience with 31 patients. Surgery, 1996, 119:384-389.

13. Rescorla FJ, Breitfeld PP, West KW, et al - A case controlled comparison of open and laparoscopic splenectomy in children. Surgery, 1998, 124: 670-676.

14. Minkes RK, Lagzdins M, Langer JC - Laparoscopic versus open splenectomy in children. J Pediatr Surg, 2000, 35: 699-701.

15. Targarona EM, Espert JJ, Balague C, et al Splenomegaly should not be considered a contraindication for laparoscopic splenectomy. Ann Surg, 1998, 228: 35-39.

16. Walsh RM, Heniford BT - Laparoscopic splenectomy for non-Hodgkin lymphoma. J Surg Oncol, 1999, 70: 116-121.

17. Totte E, Van Hee R, Kloeck I, et al - Laparoscopic splenectomy after arterial embolisation. Hepatogastroenterology, 1998, 45: 773-776.
18. Poulin EC, Mamazza J, Schlachta CM - Splenic artery embolization before laparoscopic splenectomy. An update. Surg Endosc, 1998, 12:870-875.

19. Litwin DE, Darzi A, Jakimowicz J, et al - Hand-assisted laparoscopic surgery (HALS) with the HandPort system: initial experience with 68 patients. Ann Surg, 2000, 231: 715-723.

20. Danielson PD, Shaul DB, Phillips JD, et al - Technical advances in pediatric laparoscopy have had a beneficial impact on splenectomy J Pediatr Surg 35, 2000, 15781581.

21. Al-Salem AH, Naserullah Z, Qaisaruddin S, et al Splenic complications of the sickling syndromes and the role of splenectomy. J Pediatr Hematol Oncol, 1999, 21:401-406

22. Wright JG, Hambleton IR, Thomas PW, et al Postsplenectomy course in homozygous sickle cell disease. J Pediatr, 1999, 134: 304-309.

23. Sorrells DL, Morrissey TB, Brown MF - Septic complications after splenectomy for sickle cell sequestration crisis. Pediatr Surg Int, 1998, 13: 100-103.

24. Delatte SJ, Hebra A, Tagge EP, et al - Acute chest syndrome in the postoperative sickle cell patient. J Pediatr Surg, 1999, 34: 188-191.

25. Wales PW, Carver E, Crawford MW, et al - Acute chest syndrome after abdominal surgery in children with sickle cell disease: Is a laparoscopic approach better? J Pediatr Surg, 2001, 36: 718-721.

26. Castro O, Brambilla DJ, Thorington B, et al - The acute chest syndrome in sickle cell disease: incidence and risk factors. Blood, 1994, 84: 643-649.

27. Serjeant GR, Serjeant BE-Sickle Cell Disease. Oxford University Press, 2001.

28. Goncalves MS, Nechtman JF, Figueiredo MS, Kerbauy J, Arruda VR, Sonati MF, Saad SO, Costa FF, Stoming TA. Sickle cell disease in a Brazilian population from Sao Paulo: a study of the beta s haplotypes. Hum Hered. Nov-Dec;44(6):322-7,1994.

Endereço para Correspondência:

Dr. Márcio Lopes Miranda

Rua Américo de Campos 1118

CEP 13083-040 - Cidade Universitária

Campinas - São Paulo-Brasil.

E-mail:marciomiranda@terra.com.br 